\title{
UTILIZAÇÃO DA IRRIGAÇÃO NO CONTROLE DO POTENCIAL MATRICIAL DE ÁGUA NO SOLO E SUA INFLUÊNCIA NA PRODUTIVIDADE DO CAFEEIRO
}

Maurício Cezar Resende LEITE JR ${ }^{1}$

Manoel Alves de FARIA ${ }^{2}$

${ }^{1}$ Professor Tempo integral na Universidade Vale do Rio Verde (UninCor), Doutor em Recursos Hídricos em Sistemas Agrícolas. mauricio_cezar_leite@yahoo.com.br

2Professor dedicação exclusiva na Universidade Federal de Lavras, Doutor em Engenharia Agrícola.

Recebido em: 04/01/2016 - Aprovado em: 25/04/2016 - Disponibilizado em: 30/07/2016

\begin{abstract}
RESUMO: A cafeicultura tem elevada importância econômica para o país, a cultura tem passado por avanços tecnológicos para aumento de produtividade, uma delas é o uso da irrigação, que além de suprir as necessidades hídricas da cultura, fornece a possibilidade da utilização do estresse hídrico controlado. O objetivo desse trabalho foi verificar a influência do potencial matricial da água no solo na produção do cafeeiro. O experimento foi realizado na área do Departamento de Engenharia da Universidade Federal de Lavras. O delineamento experimental utilizado foi o de blocos casualizados, com 3 tratamentos e 4 repetições. Os tratamentos utilizados constaram de manejos de irrigação, que tiveram o potencial matricial de água no solo controlado no período de agosto/2007 a julho/2009, sendo: A1 = Sem irrigação (testemunha); A2 = Irrigação o ano todo sempre que a planta consumiu $25 \%$ da disponibilidade total de água na camada de 0-20 cm; A3 = Irrigação somente nos meses abr. / maio / jun. / ago. / set. sempre que a planta consumiu $25 \%$ da disponibilidade total de água na camada de 0-20 cm. A irrigação no sul de Minas Gerais se torna essencial, em períodos que ocorrem restrições hídricas na planta, suprindo as necessidades do cafeeiro e garantindo maiores produções. O potencial matricial de água no solo influencia diretamente na produção do cafeeiro.
\end{abstract}

Palavras-chave: Restrição hídrica. Gotejamento. Sensor Watermark. Café. Produção.

\section{USE OF IRRIGATION ON THE POTENTIAL MATRIX CONTROLOF WATER AND ITS INFLUENCE ON YIELD OF COFFEE}

\begin{abstract}
The coffee has high economic importance to the country, the culture has undergone technological advances to increase productivity, one is the use of irrigation, which not only meet the crop water requirements, provides the possibility of using controlled water stress. The aim of this study was to assess the influence of matric potential of soil water in coffee production. The experiment was conducted at the Engineering Department, Federal University of Lavras. The experimental design was a randomized block design with 3 treatments and 4 replicates. The treatments consisted of irrigation management, which had a matric potential of soil water in the controlled period of August/2007 to July/2009, as follows: A1 = No irrigation (control), A2 = irrigation throughout the year when the plant consumed $25 \%$ of the total available water in 0-20 cm, A3 = irrigation only during April / May / jun. / Aug. / Set. whenever the plant consumed $25 \%$ of the total available water in $0-20 \mathrm{~cm}$. The irrigation in southern Minas Gerais becomes essential during periods water restrictions in the plant, supplying the needs of coffee and ensuring higher yields. The matric potential of soil water directly influences the production of coffee.
\end{abstract}

Keywords: fluid restriction. Drip irrigation. Watermark sensor. Coffee. Production.

\section{INTRODUÇÃO}

O cafeeiro Coffea arabica L. é uma

planta tropical de altitude, adaptada ao clima úmido com temperaturas amenas, típicas dos altiplanos da Etiópia, região considerada de origem da espécie. Normalmente, é afetado nas suas fases fenológicas pelas condições meteorológicas, principalmente a distribuição 
pluviométrica e temperatura do ar, e pela variação fotoperiódica, que interferem não apenas na fenologia, mas também, na produtividade e qualidade da bebida (CAMARGO 1985, p. 13).

Fatores climáticos, têm sido determinantes no volume da produção de café no Brasil, no passado pelas geadas e ultimamente por estiagens prolongadas. A cafeicultura é uma das mais importantes atividades agrícolas do Brasil, com relevante influência nos aspectos socioeconômicos e no agronegócio do país.

O conteúdo de água no solo é uma variável utilizada em estudos que envolvem agricultura, hidrologia e meteorologia, dentre outros. Na agricultura, essa informação é necessária para muitas aplicações, que incluem o planejamento da irrigação para o aumento da produção agrícola. Dentro deste contexto, o monitoramento do conteúdo de água no solo torna-se importante para a obtenção, por exemplo, do déficit hídrico tolerável pela planta sem prejudicar seu pleno desenvolvimento (TEIXEIRA, MORAES e SIMONETE 2005).

Segundo Matiello (2006, p.29), nas condições usuais de manejo dos cafezais, a pleno sol, como são praticadas aqui no Brasil, ocorre na maioria das regiões cafeeiras um período frio e seco de maio a setembro, ocorrendo assim, um estresse hídrico natural.

Há muita polêmica em torno da submissão do cafeeiro ao déficit hídrico, pois a planta pode ser submetida ao déficit hídrico, que pode ocorrer mesmo estando o cafeeiro instalado em solo com teor de água próximo à capacidade de campo ou mesmo dentro de solução nutritiva, segundo Rena e Maestri (2000, p. 34). Para não comprometer o desenvolvimento da planta, toda a água consumida pela evapotranspiração deve ser reposta sob a forma de precipitação ou irrigação, de forma a manter no solo umidade ideal para que as raízes consigam retirar a quantidade de água necessária, sem restrições. Assim, estudos da deficiência hídrica suportadas pelo cafeeiro sem prejudicar o seu desenvolvimento, são de fundamental importância para o projeto e o manejo de irrigação, contribuindo para o aumento de produtividade e a otimização dos recursos hídricos e energéticos, que estão cada vez mais escassos (POSSE et al., 2008).

O estudo das relações hídricas no cafeeiro é de particular interesse uma vez que pequenas reduções na disponibilidade da água podem diminuir substancialmente $\mathrm{o}$ crescimento, ainda que não se observem murchas nas folhas ou quaisquer outros sinais visíveis do déficit hídrico. Deste modo, a compreensão das relações entre a água e o cafeeiro e suas implicações ecofisiológicas, podem fornecer subsídios ao técnico e ao pesquisador, para tomadas de decisões mais fundamentadas sobre o manejo global da lavoura (SILVA e REIS 2007). 
Trabalhos de pesquisa mostram que o estresse hídrico, induz forte desfolha nas plantas, que leva a perdas de crescimento e de produção. Em cafezal em Luiz Eduardo Magalhães BA, desfolhas artificialmente efetuadas em cafeeiros, com redução na folhagem de 50 a $100 \%$, levaram perdas de produção na safra seguinte de 25 a $81 \%$ (MATIELLO 2006, p. 30).

Objetivou-se com esse trabalho controlar, através da irrigação, o potencial matricial da água no solo, verificando a sua influência na produção do cafeeiro, relatando a interferência do potencial matricial da água no solo no desenvolvimento da planta.

\section{MATERIAL E MÉTODOS}

\section{1 Área experimental, cultivar, delineamento experimental e dados climáticos}

O experimento foi realizado na área do Departamento de Engenharia da Universidade Federal de Lavras. A região de Lavras, MG, possui temperatura média anual normal de $20,4^{\circ} \mathrm{C}$, precipitação média anual de 1.460 mm (DANTAS, CARVALHO e FERREIRA 2007). De acordo com a classificação climática de Köppen a região possui clima do tipo Cwa, caracterizado por ser subtropical com inverno seco e chuvas predominantes de verão.
A cultivar Acaiá MG-1474 que foi implantada no espaçamento semi-adensado de $3,00 \mathrm{~m}$ entre linhas e $0,60 \mathrm{~m}$ entre plantas e recepada em 2004. O delineamento experimental utilizado foi $\mathrm{o}$ de blocos casualizados, com 3 tratamentos e 4 repetições. Os tratamentos utilizados constaram de manejos de irrigação realizados desde a recepa: $\mathrm{A} 1=$ Sem irrigação (testemunha); $\mathrm{A} 2$ = Irrigação $\mathrm{o}$ ano todo sempre que a planta consumiu $25 \%$ da disponibilidade total de água na camada de 020 cm; A3 = Irrigação somente nos meses abr. / maio / jun. / ago. / set. sempre que a planta consumiu $25 \%$ da disponibilidade total de água na camada de 0-20 cm.

Durante o experimento, foram monitorados os parâmetros de temperatura do ar, precipitação pluvial e evaporação do Tangue Classe A, os quais foram obtidos da estação climatológica principal de Lavras (ECP), localizada no campus da UFLA, à distância de $570 \mathrm{~m}$ do local do experimento, pertencente ao $5^{\circ}$ Distrito de Meteorologia, em convênio da UFLA com o Instituto Nacional de Meteorologia (INMET).

\subsection{Manejo de irrigação e coleta dos dados}

Os tratamentos foram irrigados quando a média do potencial matricial de água no solo atingiu os seguintes valores: A1 = Sem irrigação (testemunha); A2 =Foi irrigado quando a média dos sensores $(10 \mathrm{~cm}$ 
profundidade) atingiu $21 \mathrm{kPa} ; \mathrm{A} 3=$ Foi irrigado nos meses de abr / mai / jun / ago / set quando a média dos sensores $(10 \mathrm{~cm}$ profundidade) atingiu $22 \mathrm{kPa}$.

O potencial matricial da água no solo foi obtido através de sensores, do tipo Watermark $^{\circledR}$. Em julho/2007 foram instalados em cada uma das parcelas experimentais 2 sensores no centro da faixa molhada de irrigação, um a $10 \mathrm{~cm}$ de profundidade, e outro, a $30 \mathrm{~cm}$ de profundidade, distanciados em $10 \mathrm{~cm}$ entre si. Foram feitas 24 leituras de potencial matricial de água no solo diariamente para cada sensor as quais foram armazenadas por um Datalogger e descarregados no computador pelo programa Watergraph. Os sensores Watermark $^{\circledR}$, monitoraram o potencial matricial da água no solo, no período de agosto/2007 a julho/2009.

A colheita do café nos anos de 2008, 2009 e 2010 foram feitas de forma manual sobre "pano". Após a derriça, obteve-se o volume total e o peso total do café colhido. Retirou-se uma amostra de 10 litros de frutos que foi pesada e colocada em sacos plásticos, tipo rede, onde o café foi seco em bancadas suspensas ao ar livre até que atingiu umidade na faixa de $11 \%$. Após a secagem as amostras foram beneficiadas e pesadas. Com os dados da parcela relacionados com os dados da amostra beneficiada, estimou-se a produtividade do cafeeiro.

A análise estatística foi realizada pelo programa Sisvar ${ }^{\circledR}$ (FERREIRA 2003) versão
4.0. As médias entre os tratamentos foram comparadas pelo teste de Scott-Knott $(\mathrm{P}<0,05)$.

\section{RESULTADOS E DISCUSSÃO}

\subsection{Variação sazonal nos parâmetros climáticos}

O clima atua e interfere no cafezal e no solo principalmente através da precipitação, vento, temperatura, umidade do ar. Um dos fatores importante para a irrigação nesse tipo de cultura é o envolvimento da temperatura com o vento, esses elementos determinam à evaporação do solo e a transpiração das plantas. $\mathrm{Na}$ junção desses elementos climáticos chaga-se a evapotranspiração que corresponde praticamente a quase toda totalidade do consumo de água pela lavoura (MENDONÇA et al. 2006).

As variações sazonais dos parâmetros climáticos estão apresentadas na Figura 1, que demonstra valores mensais das precipitações pluviais (PREC.), evaporação do Tangue Classe A (TCLA) e temperatura média mensal (T. MÉD.), no período de agosto de 2007 a julho de 2009.

No período de agosto/2007 a julho/2008, foram registrados resultados da ordem de 1245,4 $\mathrm{mm}$ para precipitação acumulada. Verifica-se pela Figura $1 \mathrm{~A}$ que o maior volume de precipitações ocorreu no 
mês de janeiro $(263 \mathrm{~mm})$ e a menor precipitação acumulada mensal nos meses de agosto, setembro e julho $\left(\begin{array}{lll}0 & \mathrm{~mm}\end{array}\right)$. A temperatura média anual foi de $20,4{ }^{\circ} \mathrm{C}$, variando de $15,9^{\circ} \mathrm{C}$ na média do mês julho, ao máximo de $23,0^{\circ} \mathrm{C}$ na média de dezembro.

Na Figura 1B, são apresentados, os dados correspondentes ao período de agosto/2008 a julho/2009. O mês de dezembro apresentou o maior volume de precipitações pluviais $(419,4 \mathrm{~mm})$, e o menor volume foi registrado em agosto e julho (13,9 $\mathrm{mm}$ ), totalizando um acumulado de 1671,8 $\mathrm{mm}$ de precipitações pluviais no período. A temperatura média do ar nesse período manteve-se semelhante ao ano anterior com média anual de $20,5^{\circ} \mathrm{C}$, apresentando maior e menor valor de média mensal respectivamente, nos meses de outubro $(23,3$ $\left.{ }^{\circ} \mathrm{C}\right)$ e junho $\left(16,3^{\circ} \mathrm{C}\right)$.

FIGURA 1 - Valores mensais das precipitações pluviais (PREC.), evaporação do Tangue Classe A (TCLA) e temperatura média mensal (T. MÉD.) no período de agosto/2007 a julho/2008 (A) e no período de agosto/2008 a julho/2009 (B). UFLA, Lavras - MG/ 2010.

A

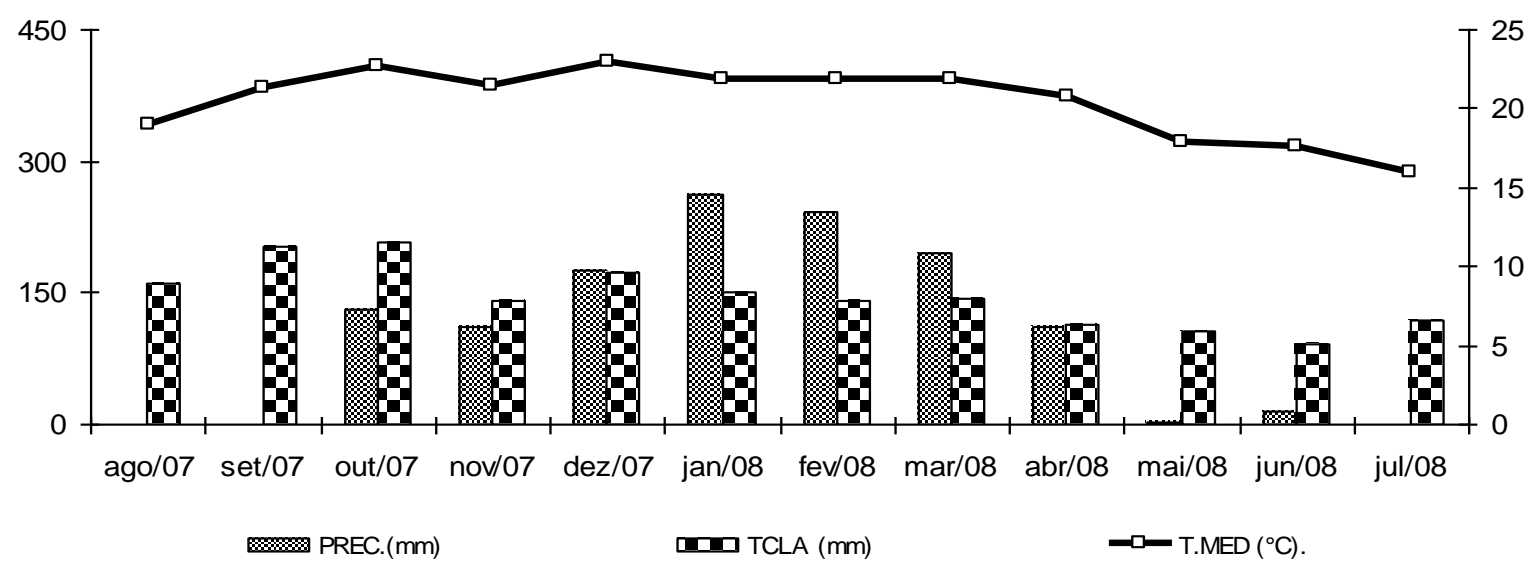

B

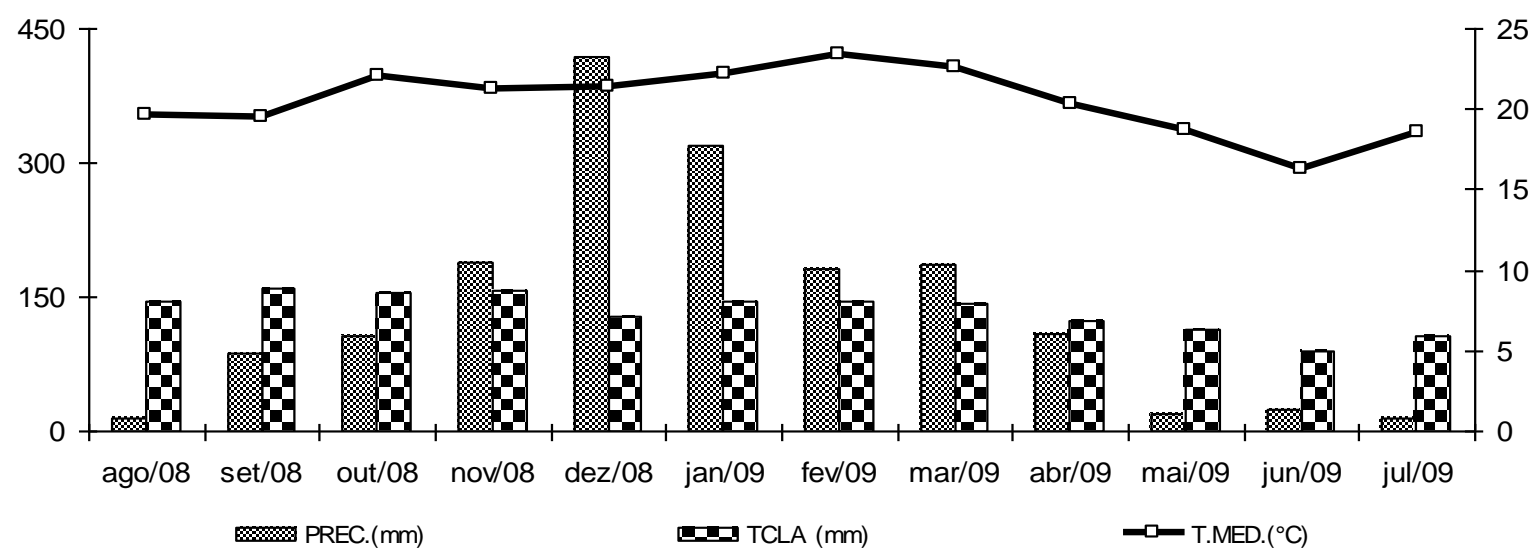

Fonte: Próprio autor. 
Confrontando os resultados desses dois períodos, verificam-se semelhanças com trabalho realizado por Dantas, Carvalho e Ferreira (2007), que estudaram as variações ambientais no município de Lavras, MG, avaliando a tendência de dados climáticos recentes de 14 anos (1991-2004) e comparando-os com os valores da série histórica do período de 1961 a 1990. Os autores relatam que, para a série observada de 1991-2004, os valores de temperatura ficaram maiores. A temperatura média anual aumentou de $19,4^{\circ} \mathrm{C}$ para $20,4^{\circ} \mathrm{C}$, variando de $17,1^{\circ} \mathrm{C}$, em julho a $22,8^{\circ} \mathrm{C}$, em fevereiro. A precipitação anual de $1.530 \mathrm{~mm}$ foi reduzida para $1.460 \mathrm{~mm}$ na série observada de 14 anos, sendo os maiores e os menores valores de precipitação alterados para $321 \mathrm{~mm}$, em janeiro e $7 \mathrm{~mm}$, em julho.

A temperatura media do ar não teve variações entre esses dois anos avaliados e com o trabalho desenvolvido por Dantas, Carvalho e Ferreira (2007), mas ocorreu uma diferença no volume de precipitações, sendo o período de agosto/2008 a julho/2009, 34\% e $15 \%$ maior respectivamente ao período agosto/2007 e julho/2008 e a série de Dantas, Carvalho e Ferreira (2007). Esse maior volume de precipitações foi mais bem distribuído durante os meses agosto/2008 a abril/2009, quando comparado com o período anterior, suprindo por um período mais longo as necessidades hídricas do cafeeiro.
A região de Lavras apresenta volumes significativos de precipitação pluvial, a partir de outubro até março, compreendendo em parte o período vegetativo do cafeeiro, que inicia em setembro estendendo-se até junho (CAMARGO E CAMARGO 2001), justificando o uso da irrigação nesses períodos de déficit hídrico. Segundo Evangelista, Carvalho e Sediyama (2002) no Brasil, as boas regiões produtoras de café estão localizadas onde ocorrem mais de 150 mm de chuva por mês, no período de florescimento, formação e maturação dos frutos, que compreende os meses de setembro a junho nas regiões produtoras do Estado de Minas Gerais, ou seja, o período de renovação de galhos e folhas. Santinato, Fernandes André e Fernandes (2008), verificou que áreas com déficit hídrico mensal entre 100 a 150 mm, são consideradas aptas, para cultivo do cafeeiro arábica, porém, com irrigação ocasional.

\subsection{Potencial matricial de água no solo}

$\mathrm{Na}$ Figura 2 observa-se $\mathrm{o}$ comportamento dos dados do potencial matricial de água no solo para cada tratamento ao longo dos dois anos de monitoramento. No tratamento A1 (sem irrigação), verifica-se que o comportamento do gráfico é influenciado diretamente pelas precipitações, tendo valores maiores de 
potencial matricial de água no solo nos períodos chuvosos, confirmando a confiabilidade de resposta dos sensores Watermark a aplicação de água. A partir de outubro/2007, iniciou as precipitações, realizando recarga de água no solo na camada avaliada. De novembro/2007 a meados de abril/2008, o solo apresentou potencial mátrico médio de $-29 \mathrm{kPa}$, demonstrando que a planta do tratamento $\mathrm{A} 1$, não teve dificuldade em atender suas necessidades hídricas nesse período.

No tratamento A2 irrigado durante todo o ano, observa-se que o gráfico teve um comportamento com pequenas variações, promovido pelo manejo de irrigação adotado. Durante todo o período avaliado, o solo manteve um valor de potencial matricial próximo ao estabelecido pelo manejo de irrigação $(-21 \mathrm{kPa})$, mesmo nos períodos em que não ocorriam precipitações.

No caso do tratamento A3, suas irrigações foram programadas para o período de seca na região, que segundo Matiello (2006) ocorre de abril a setembro, sendo que nesse manejo há a proposta de aplicação de déficit hídrico no mês de julho (sem irrigações). Nesses meses o potencial mátrico de água no solo manteve-se próximo ao estabelecido no manejo de irrigação (-22 $\mathrm{kPa}$ ), chegando ao um valor mínimo em julho (suspensão das irrigações) de -235 e $-231 \mathrm{kPa}$ respectivamente para os anos de 2008 e 2009. Nos demais meses (outubro a março) onde foram suspensas as irrigações, o potencial matricial de água no solo foi influenciado diretamente pelas precipitações pluviais. Esses valores apresentaram-se inferiores aos estabelecidos pelo manejo de irrigação, atingindo uma média $-38 \mathrm{kPa}$ (outubro/2007 a março/2008) e $\quad-30 \mathrm{kPa}$ (outubro/2008 a março/2009), mantendo-se com valores elevados, o que não propiciou restrição hídrica elevada às plantas desse tratamento.

Segundo Camargo e Camargo (2001) a fase fenológica do cafeeiro de vegetação e formação das gemas vegetativas, para $01^{\circ}$ ano fenológico, e a fase de florada, chumbinho, expansão e granação dos frutos para o $2^{\circ}$ ano fenológico do cafeeiro, ocorrem entre os meses de setembro a março. Nesse período o cafeeiro deve ter suas necessidades hídricas supridas, sem ocorrência de déficit hídrico elevado na planta, proporcionando que a planta mantenha suas atividades metabólicas ao máximo. Qualquer déficit hídrico, que venha a ocorrer nesse período, prejudicará as produções futuras nas próximas duas colheitas.

Analisando o período crítico de maior necessidade hídrica do cafeeiro (setembro/2007 a março/2008), o tratamento A1 apresenta uma média de potencial matricial de água no solo de $-86,73 \mathrm{kPa}$, nesse intervalo de tempo toda a entrada de água no solo se deu pelas precipitações. No inicio de setembro/2007, o potencial mátrico era de $250 \mathrm{kPa}$, sendo que as precipitações ocorridas 
em outubro realizaram a recarga de água no solo De acordo com o aumento da freqüência que as precipitações ocorriam, se dava a variação do potencial mátrico de água no solo, conservando-o em valores mais altos. Os tratamentos irrigados A2 e A3 apresentaram, uma média do potencial matricial de água no solo de $-15,56$ e $-35,49 \mathrm{kPa}$ respectivamente. $\mathrm{O}$ tratamento A2, apresentou potencial mátrico maior que o estabelecido pelo manejo de irrigação. Esse fato se deveu à manutenção da umidade do solo pelas irrigações e às chuvas, deixando assim o solo mais próximo da capacidade de campo.

No segundo ano analisado, o período de setembro/2008 a março/2009, fase de maior necessidade hídrica do cafeeiro, o tratamento não irrigado (A1), apresentou uma média de potencial matricial de água no solo de $-52,38 \mathrm{kPa}$. Nesse ano de análise, a média do potencial matricial de água no solo para o tratamento A1, apresentou-se $40 \%$ maior que o ano anterior. Esse fato está atrelado ao volume de precipitações serem superior em $25 \%$ em relação ao mesmo período anterior, e a ocorrência de precipitações nos meses de agosto e setembro/2008, repondo de maneira gradativa a água no solo. $\mathrm{O}$ cafeeiro desse tratamento nesse ano, sofreu uma menor restrição hídrica, podendo proporcionar ganhos de produção na colheita de 2010. Nos tratamentos irrigados, a média do potencial matricial do solo, apresentou-se próxima aos valores do período anterior, com uma média de -21 e $-27 \mathrm{kPa}$ para os tratamentos A2 e A3 respectivamente, mantendo a umidade no solo praticamente constante ao longo do ano, independente do volume de precipitações ocorridas.

FIGURA 2 - Valores do Potencial Matricial de água no solo, para os tratamentos de irrigação A1 (não irrigado), A2 (irrigado o ano todo) e A3 (irrigado nos meses de abr/mai/jun/ago/set.), no período de agosto/2007 a julho/2009. UFLA, Lavras - MG/ 2010.

Potencial Matricial de Água no Solo

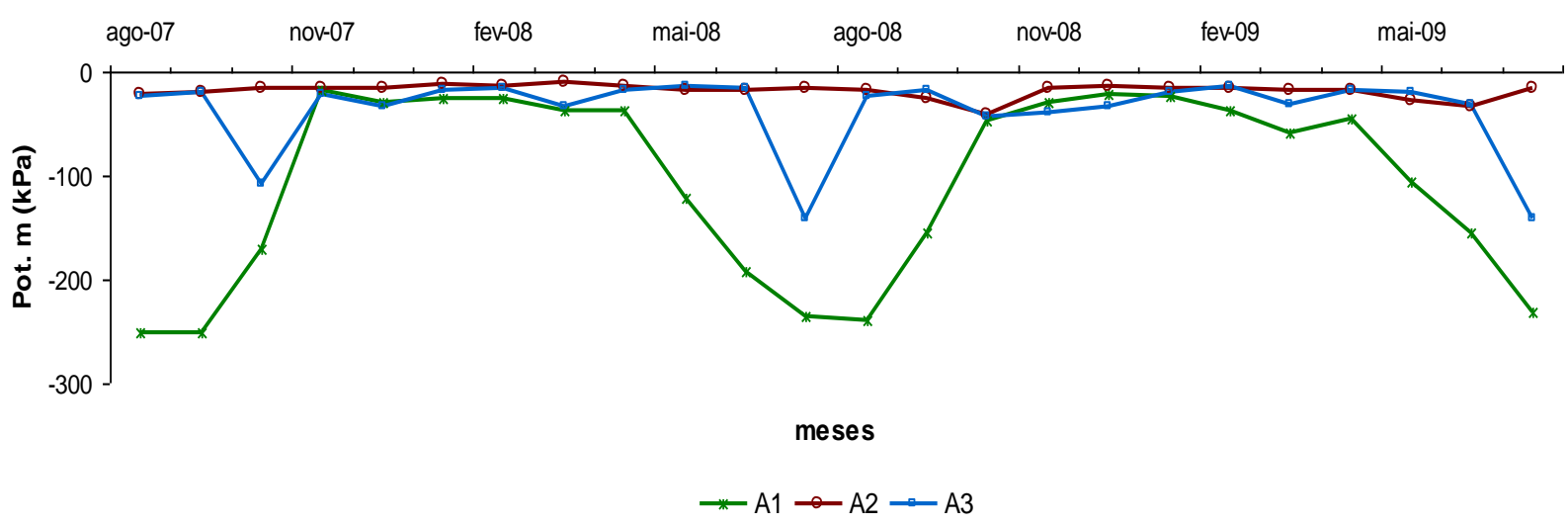

Fonte: Próprio autor. 
Segundo Camargo e Camargo (2001) o período entre abril a agosto na fenologia do cafeeiro ocorre, a $2^{\text {a }}$ fase vegetativa, quando há indução das gemas vegetativas dos nós formados na $1^{\mathrm{a}}$ fase para gemas reprodutivas. No final da $2^{\mathrm{a}}$ fase, em julho e agosto, as plantas entram em relativo repouso, com formação de um ou dois pares de folhas pequenas. Nesse período dá-se início a $5^{\mathrm{a}}$ fase, do segundo ano fenológico, quando há a maturação dos frutos. A $6^{\mathrm{a}}$ fase (senescência e morte dos ramos produtivos não primários) ocorre em julho e agosto. Essas fases da fenologia cafeeira em que a planta não tem exigência hídrica, sendo recomendado em alguns estudos à aplicação de déficit hídrico na planta para uniformização da floração. Esse intervalo de tempo, corresponde ao período frio e seco na região de Lavras segundo Matiello (2006).

\section{O tratamento A1 apresentou uma} média de potencial matricial de água no solo de $-165 \mathrm{kPa}$ no período de abril a agosto/2008, proporcionando restrição na disponibilidade de água para a planta por período prolongado, sendo que a recarga de água no solo só iniciou com o inicio das precipitações, época em que o potencial matricial atingiu um mínimo de $-239 \mathrm{kPa}$. Os tratamentos irrigados apresentaram, uma média do potencial matricial de água no solo de -16 e $-42 \mathrm{kPa}$, respectivamente para os tratamentos A2 e A3. O tratamento A3 apresentou valor menor que o estabelecido pelo manejo de irrigação. A ocorrência desse valor foi influenciado pela suspensão das irrigações no mês de julho (-165 kPa), diminuindo a média do potencial matricial de água no solo entre os meses de abril a agosto/2008.

De acordo com Matiello (1991, p. 320) para o Estado de Minas Gerais, no período de vegetação e frutificação, que se estende de outubro a maio, o cafeeiro necessita de maior umidade no solo e, na fase de colheita e repouso, de junho a setembro, esta necessidade é pequena, podendo o solo ficar com menos umidade, sem grandes prejuízos para a planta.

\subsection{Produção}

A colheita de 2008 representou um ano de bienalidade negativa, não ocorrendo diferenças estatísticas entre os tratamentos (Tabela 1).

$\mathrm{Na}$ colheita de 2009, obteve-se diferença estatística entre os tratamentos de irrigação, sendo os tratamentos A2 e A3 iguais e com maior produção quando comparados ao tratamento não irrigado (Tabela 1). O tratamento A2 proporcionou um acréscimo de $41 \%$ na produção em relação ao tratamento sem irrigação. Autores como Rezende et al. (2006) e Gomes, Lima e Custódio (2007) relatam que a adoção da irrigação tem proporcionado incrementos consideráveis na produtividade das lavouras cafeeiras, o que tem justificado a adoção desta 
técnica por parte dos produtores. Resultados semelhantes também foram encontrados por Silva, Teodoro e Melo (2008) avaliando a produtividade e o rendimento das quatro primeiras safras do cafeeiro Rubi MG-1192 sob sistema de irrigação por gotejamento em Uberlândia, MG.

TABELA 1 - Produção obtida nos tratamentos de irrigação, nas colheitas de 2008, 2009, 2010 e acumulada. UFLA, Lavras - MG, 2010.

\begin{tabular}{cccc}
\hline $\begin{array}{c}\text { Manejo de } \\
\text { Irrigação }\end{array}$ & $\mathbf{2 0 0 8}$ & Produção (sc/ha)* \\
\hline A1 & $1,92 \mathrm{C}$ & $\mathbf{2 0 0 9}$ & $\mathbf{2 0 1 0}$ \\
A2 & $3,23 \mathrm{C}$ & $88,59 \mathrm{~b} \mathrm{~A}$ & 42,17 a B \\
A3 & $2,52 \mathrm{C}$ & 124,72 a A & 17,74 b B \\
\hline
\end{tabular}

*Média seguidas por letras diferentes na vertical (minúsculas) e na horizontal (maiúsculas), diferem entre si pelo teste de Scott-Knott (5\%).

Fonte: Próprio autor.

O período de crescimento vegetativo que gerou a produção de 2009, correspondente aos meses de setembro/2007 a março/2008. Este período teve um menor volume de precipitações pluviais e por um período menor (Figura 1A), proporcionando uma maior restrição hídrica ao tratamento não irrigado, podendo ter diminuído o potencial vegetativo da planta, causando uma conseqüente diminuição da produção do ano de 2009, visto que na fase reprodutiva correspondente à colheita de 2009 não houve nenhum fator que justificasse a baixa produção do tratamento A1. Gomes, Lima e Custódio (2007) comentam uma possível explicação para a acentuada redução da produtividade do tratamento testemunha em relação aos irrigado ser o forte déficit hídrico ocorrido nos meses de abril a junho do ano anterior, vindo a comprometer a safra seguinte.
Com relação à colheita de 2010, o tratamento A1 (sem irrigação) demonstrou-se mais produtivo estatisticamente quando comparado aos tratamentos irrigados. A produção de 2010, foi representativa do crescimento ocorrido de setembro/2008 a março/2009, período satisfatório ao bom desenvolvimento vegetativo do cafeeiro. A maior produção do tratamento A1 nesse ano, pode ser justificada pela planta ter sido submetida a uma menor restrição hídrica, proporcionando um crescimento vegetativo igualitário entre os tratamentos não irrigados e irrigados, além de a planta ter se depauperado menos por ter apresentado uma produção menor no ano de 2009. Autores como Lima, Custódio e Gomes (2008) encontraram resultados parecidos onde estudaram, por cinco safras, a produtividade do cafeeiro e o rendimento do café irrigado por pivô central em Lavras, MG. Os autores 
discutem que uma menor intensidade de déficit hídrico pode ter contribuído para elevada produtividade das plantas não irrigadas durante a quarta safra, igualando esse tratamento aos irrigados.

Como a fenologia da produção do cafeeiro dura dois anos, deve-se analisar a influencia do potencial matricial no solo a longo prazo. Silva, Teodoro e Melo (2008) relatam ser imprescindível avaliar o efeito do déficit hídrico sobre a produção do cafeeiro ao longo de vários anos a fim de se obterem respostas mais abrangentes. De forma similar, Lima, Custódio e Gomes (2008) e Custódio, Gomes e Lima (2007) concluem que experimentos que avaliem o efeito da irrigação sobre a produtividade e rendimento do cafeeiro e a classificação do café deva durar, no mínimo, cinco anos.

\section{CONCLUSÕES}

A irrigação no sul de Minas Gerais se torna essencial, em períodos que ocorrem restrições hídricas na planta, suprindo as necessidades do cafeeiro e garantindo maiores produções.

O potencial matricial de água no solo influencia diretamente a produção do cafeeiro, quanto menor for a submissão das plantas a restrição hídrica, maior será a possibilidade de aumentos na produtividade do cafeeiro.

A bienalidade de produção do cafeeiro interfere diretamente nas análises de produção anual, visto que nos anos de bienalidade positiva os tratamentos irrigados proporcionam maiores produções.

\section{REFERÊNCIAS}

CAMARGO, A. P. de. O clima e a cafeicultura no Brasil. Informe Agropecuário, Belo

Horizonte, v. 11, n. 126, p.13-26, 1985

CAMARGO, A.P.; CAMARGO, M.B.P. Definição e esquematização das fases fenológicas do cafeeiro arábica nas condições tropicais do Brasil. Bragantia, Campinas, v. 60, n. 1, p. 65-68, 2001.

CUSTÓDIO, A. A. de P.; GOMES, N. M.; LIMA, L. A. Efeito da irrigação sobre a classificação do café. Engenharia Agrícola, Jaboticabal, v. 27, n. 3, p. 691-701, set./dez. 2007.

DANTAS, A. A. A., CARVALHO, L. G. de e FERREIRA, E. Classificação e tendências climáticas em Lavras, MG. Ciência e agrotecnologia, Dez 2007, vol.31, no.6, p.1862-1866. ISSN 1413-7054 EVANGELISTA, A. W. P.; CARVALHO, L., G.; SEDIYAMA, G. C. Zoneamento climático associado ao potencial produtivo da cultura do café no Estado de Minas Gerais.

Revista Brasileira de Engenharia Agrícola e Ambiental, Campina Grande, v.6, n.3, p. 445-452, 2002

FERREIRA, D. S. SISVAR versão 4.6 (Build 65). Lavras: Dex/ UFLA. 2003.

GOMES, N. M.; LIMA, L. A.; CUSTÓDIO, A. A. de P. Crescimento vegetativo e produtividade do cafeeiro irrigado no sul do Estado de Minas Gerais. Revista Brasileira de Engenharia Agrícola e Ambiental. Campina Grande, v.11, n. 6, p.564-570, 2007.

LIMA, L. A.; CUSTÓDIO, A. A. de P.; GOMES, N. M. Produtividade e rendimento 
do cafeeiro nas cinco primeiras safras irrigado por pivô central em Lavras, MG. Ciência e Agrotecnologia. Lavras, v.32, n. 6, p. 1832 1842, nov./dez., 2008.

MATIELLO, A. W. R. Estresso ou não meu cafezal. Revista brasileira de tecnologia cafeeira: Coffea, Varginha-MG, III, $n^{\circ} 10$, p. 29-30, 2006 a.

MATIELLO, J. B. O café: do cultivo ao consumo. Globo Rural, Coleção do agricultor - Grãos, 320 p., 1991

MENDONÇA, J.C.; SOUSA, E.F.; ANDRE, R.G.B.; BERNARDO, S. Coeficientes do tanque Classe "A" para a estimativa da evapotranspiração de referência, em Campos dos Goytacazes, RJ. Revista Brasileira de Agrometeorologia, Santa Maria, v.14, p.123-128, 2006

POSSE, R. P.; BERNARDO, S.; SOUSA, E. F. DE; GOTTARDO, R. D. EVAPOTRANSPIRAÇÃO E COEFICIENTE DA CULTURA DO MAMOEIRO.

Engenharia Agrícola, Jaboticabal, v.28, n.4, p.681-690, out./dez. 2008

RENA, A. B.; MAESTRI, M. Relações hídricas no cafeeiro. ITEM: Irrigação \& Tecnologia Moderna, Brasília, n. 48, p. 3441, set. 2000.

REZENDE, F. C.; OLIVEIRA, S. dos R.; FARIA, M. A. de; ARANTES, K. R.

Características produtivas do cafeeiro (Coffea arabica L. cv., Topázio MG -1190), recepado e irrigado por gotejamento. Coffea Science, Lavras, v.1, n.2, p.103-110, jul./dez.2006.

SANTINATO, R.; FERNANDES, A. L. T.; FERNANDES, D. R.; Irrigação na cultura do café; O lutador, $2^{\mathrm{a}}$ ed.; Belo Horizonte - MG, 2008, 476p.

SILVA, J. G. F.; REIS, E. F. dos. Irrigação do cafeeiro Conilon, In: FERRÃO, R. G.;

FONSECA, A. F. A. da; BRAGANÇA, S.

M.; FERRÃ̃, M. A. G.; MUNER, L. H.

De, Café Conilon,Vitória, ES: Incaper, 2007.
SILVA, C. A. da; TEODORO, R. E. F.; MELO, B. de. Produtividade e rendimento do cafeeiro submetido a lâminas de irrigação.

Pesquisa Agropecuária Brasileira, Brasília, v. 43, n.3, p.387-394, mar. 2008.

TEIXEIRA, C. F. A.; MORAES, S. O.; SIMONETE, M. A. Desempenho do tensiômetro, TDR e sonda de nêutrons na determinação da umidade e condutividade hidráulica do solo. Revista Brasileira de Ciência do Solo, v.29, n.2, p.161-168, 2005. 